\title{
How wide is the clinical spectrum of the acrocallosal syndrome? Report of a mild case
}

\author{
Licia Turolla, Maurizio Clementi, Romano Tenconi
}

\begin{abstract}
A boy presenting with an incomplete form of the acrocallosal syndrome is described. The syndrome shows clinical variability and it is stressed that none of the components is constant and facial dysmorphism is not always characteristic.
\end{abstract}

In 1979 Schinzel ${ }^{1}$ described a condition characterised by postaxial polydactyly, hallux duplication, absence of the corpus callosum, macrocephaly, and severe mental retardation, which was subsequently designated 'acrocallosal syndrome' (ACS). ${ }^{2}$ Autosomal recessive inheritance is strongly suggested by parental consanguinity in four sporadic cases ${ }^{3-5}$ and by two affected sisters with normal, unrelated parents. ${ }^{6}$ To date, 17 cases (13 sporadic patients, two sisters, and two first cousins) have been reported, and clinical findings in three unpublished cases were referred to by Schinzel. ${ }^{7}$ After the first report, numerous additional findings have been described $^{4}$ 8-10 (table), but the minimal diagnostic criteria have not yet been established.

This report concerns a patient with all the components of ACS except preaxial polydactyly, which is considered to be a consistent feature of this syndrome, and addresses the variability of the phenotypic spectrum and diagnostic criteria in ACS.

\section{Case report}

This 6 month old male child (figure) was the first born

Servizio di Genetica Medica, Dipartimento di Pediatria, Università di Padova, Via Giustiniani 3, 35128 Padova, Italy.

L Turolla, M Clementi, R Tenconi

Correspondence to Dr Turolla.

Received for publication 11 December 1989.

Revised version accepted for publication 6 March 1990.
Phenotypic spectrum of acrocallosal syndrome.

\begin{tabular}{lrr}
\hline & No & $\%$ \\
\hline Most frequent findings & & \\
Craniofacial dysmorphism & $18 / 18$ & 100 \\
Total or partial absence of corpus callosum & $21 / 21$ & 100 \\
Severe mental retardation & $19 / 20$ & 95 \\
Polydactyly & $10 / 21$ & 48 \\
$\quad$ Pre- and postaxial & $6 / 21$ & 29 \\
$\quad$ Postaxial & $5 / 21$ & 24 \\
$\quad$ Preaxial & & \\
& $12 / 18$ & 67 \\
Additional findings & & \\
Ocular anomalies & & \\
$\quad$ Strabismus (6), retinal pigment & \\
$\quad$ anomaly (3), optic atrophy (2), & $7 / 11$ & 64 \\
$\quad$ nystagmus (1) & $10 / 18$ & 56 \\
Genital anomalies (males) & $9 / 18$ & 50 \\
Inguinal, umbilical, or epigastric hernia & $6 / 18$ & 33 \\
Skeletal anomalies & $6 / 18$ & 33 \\
Seizures & $6 / 18$ & 33 \\
Cardiovascular anomalies & & \\
Cerebral anomalies & $5 / 18$ & 28 \\
$\quad$ (other than agenesis of corpus callosum) & $3 / 18$ & 17 \\
Cleft lip/palate, cleft palate & $2 / 18$ & 11 \\
\hline Nipple anomalies & & \\
Visceral anomalies &
\end{tabular}

to healthy and unrelated parents (30 year old father and 25 year old mother). One previous and two subsequent pregnancies had miscarried for unknown 은 reasons. During gestation of the proband, fetal movements began at 4.5 months and were considered to be normal. An ultrasound examination at 8 months' gestation showed retarded fetal growth and unidentified therapy was prescribed. Labour began spontaneously at 38 weeks, but owing to fetal distress, caesarean section was performed. Dark amniotic fluid and a small placenta were reported; birth weight was $2470 \mathrm{~g}$ (3rd to 10th centile) and length $49.0 \mathrm{~cm}$ (25th to 50 th centile).

Apgar scores were 7 and 9 at one and five minutes, respectively. At birth, a right club foot, varus left foot, and bilateral postaxial polydactyly of the toes were noted. When the patient was 2 months old, a 


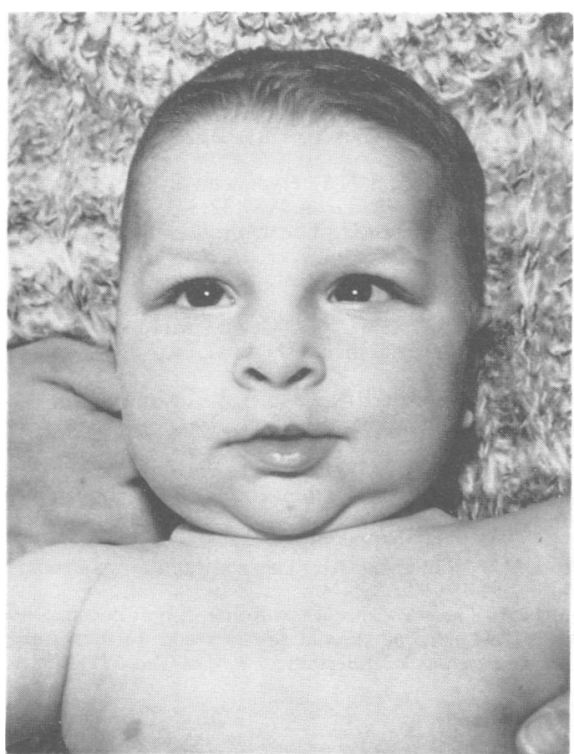

Facial appearance of the proband at 6 months of age, showing bulging forehead, convergent strabismus, wide nasal bridge, anteverted nostrils, simple, prominent philtrum, thin upper lip, and prominent lower lip.

right inguinal hernia, cryptorchidism, a left retractile testis, and psychomotor retardation became evident. He underwent a hernia operation and orchidopexy at 5 months of age. At 6 months, his length was $65.0 \mathrm{~cm}$ (10th to 25 th centile), weight was $7.5 \mathrm{~kg}$ (50th centile), and head circumference was $41.0 \mathrm{~cm}(-2 \cdot 0$ SD). The anterior fontanelle was almost closed and slight plagiocephaly with bulging forehead, slight facial asymmetry, flat supraorbital ridges, periorbital fullness, and alternating convergent strabismus were noted. The inner canthal distance was $2.6 \mathrm{~cm}$ (75th to 90th centile), the outer canthal distance was $7 \cdot 0 \mathrm{~cm}$ (50th to 75th centile), and the palpebral fissure length was $2 \cdot 2 \mathrm{~cm}$ (50th to 75 th centile). Posteriorly rotated ears, a wide nasal bridge, anteverted nostrils, a simple, prominent philtrum, a thin upper lip, a prominent lower lip, minimal micrognathia, and a high palate were also present. In addition, a bilateral single transverse palmar crease, narrow fingernails, slightly varus right foot, a wide gap between the first and second toes, proximal syndactyly of the second and third toes, and bilaterally duplicated first phalanx of the fifth toe were observed. Cardiovascular, abdominal, and joint findings were normal. The child had poor head control, hypertonic lower limbs, mild hyperreflexia, and occasional opisthotonic posturing. $X$ rays of the hands and feet showed no abnormalities other than postaxial polydactyly of the toes. An EEG showed slight asymmetry during sleep. Cerebral ultrasonography at birth and CT scan at 3 months of age both showed findings suggesting hypoplasia or agenesis of the corpus callosum. Results of fundoscopy, abdominal ultrasonography, and karyotype analysis (RHG banding, 11 peripheral lymphocytes examined) were normal.

\section{Discussion}

The clinical manifestations of ACS are very striking in almost all the reported patients (table), probably because the less typical cases are not diagnosed. The diagnostic criteria proposed by Nelson and Thomson ${ }^{11}$ were more recently revised by Schinzel and Kaufmann, ${ }^{6}$ who considered the combination of agenesis of the corpus callosum and polydactyly less consistent than craniofacial dysmorphism and severe mental retardation.

Preaxial polydactyly was thought to be the typical limb anomaly, but five patients showing only postaxial polydactyly, as in our case, have recently been reported. $^{35} 1012$ Also based on our observation and the published reports, craniofacial dysmorphism is neither characteristic nor constant; all reported patients had a prominent forehead, but 13/21 and $15 / 18$ cases respectively had macrocephaly (head circumference $>2 \mathrm{SD}$ ) and hypertelorism. Our patient shows three major components of the syndrome and some dysmorphic features, but not hallux duplication, nor the less frequent anomalies described in ACS. Our case is the fifth patient with mild expression of $\mathrm{ACS}^{3} 5^{12} \mathrm{~A}$ previously reported case had a first cousin with the fully expressed syndrome, ${ }^{12}$ which confirms the phenotypic variability in ACS and indicates that the absence of a single major anomaly does not exclude the diagnosis. Therefore, the diagnosis can be made even without a positive family history in patients with an incomplete clinical picture. The differential diagnosis of ACS includes several entities. A chromosomal anomaly should always be ruled out, as well as Greig cephalopolysyndactyly, hydrolethalus, Meckel, and Smith-Lemli-Opitz syndromes. The inheritance of ACS is still unclear. It was initially considered to be an autosomal dominant trait (McKusick 1986, 10105), but was recently classified as an autosomal recessive (McKusick 1988, 20099) on the basis of parental consanguinity and two affected sisters with normal parents. However, some findings indicate genetic heterogeneity. Only one sibship with two affected sibs has been described, but multiplex families havè greater probability of ascertainment in rare autosomal recessive conditions. The high frequency of parental consanguinity (four of 19 families) and the small number of reported cases suggest a low gene frequency. Although the observation of one set of affected first cousins could point to a high gene frequency, this could be explained instead by a local high gene incidence, as these subjects live in an 
isolated community in a mountain valley of Switzerland.

Further descriptions of ACS patients will be useful for a better understanding of the syndrome's clinical variability, and to define the pattern of inheritance. The identification of patients with a less severe clinical picture of ACS enables genetic counselling of the families as well as prenatal diagnosis by recognition of cerebral malformations or polydactyly or both on ultrasonography.

We wish to thank Professor Albert Schinzel for his opinions and suggestions concerning this case.

1 Schinzel A. Postaxial polydactyly, hallux duplication, absence of the corpus callosum, macrencephaly and severe mental retardation: a new syndrome? Helv Paediatr Acta 1979;34:141-6.

2 Schinzel A, Schmid W. Hallux duplication, postaxial polydactyly, absence of the corpus callosum, severe mental retar- dation, and additional anomalies in two unrelated patients: a new syndrome. Am $\mathcal{F}$ Med Genet 1980;6:241-9.

3 Philip N, Apicella N, Lassman I, Ayme S, Mattei JF, Giraud F. (․ The acrocallosal syndrome. Eur f Pediatr 1988;147:206-8.

4 Salgado LJ, Ali CA, Castilla EE. Acrocallosal syndrome in a girl born to consanguineous parents. Am $\mathcal{F}$ Med Genet 1989;32: 298-300.

5 Temtamy SA, Meguid NA. Hypogenitalism in the acrocallosal syndrome. Am $\mathcal{F}$ Med Genet 1989;32:301-5.

6 Schinzel A, Kaufmann U. The acrocallosal syndrome in sisters. Clin Genet 1986;30:399-405. 7 Schinzel A. Editorial comment. Acrocallosal syndrome. Am $\mathcal{f} \frac{\bar{\sigma}}{\bar{\Phi}}$

8 Casamassima AC, Beneck D, Gewitz MH, et al. Acrocallosal

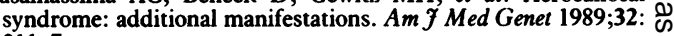
311-7.

9 Moeschler JB, Pober BR, Holmes LB, Graham JM Jr. Acrocallosal syndrome: new findings. Am J Med Genet 1989;32: 306-10.

10 Sanchis A, Cervero' L, Martinez A, Valverde C. Duplication of hands and feet, multiple joint dislocations, absence of corpus callosum and hypsarrhythmia: acrocallosal syndrome? Am $\mathcal{f}$ Med Genet 1985;20:123-30.

11 Nelson MM, Thomson AJ. The acrocallosal syndrome. $A m \mathcal{F} \mathrm{N}$ Med Genet 1982;12:195-9.

12 Schinzel A. The acrocallosal syndrome in first cousins: widening $\infty$ of the spectrum of clinical features and further support for $G$ autosomal recessive inheritance. $\mathcal{J}$ Med Genet 1988;25:332-6. 